\title{
Correction to:"Careful" reprogramming of baclofen intrathecal programmable synchromed infusion pumps at their replacement in a series of 156 patients
}

\author{
Ivano Dones $^{1} \cdot$ Giuseppe Messina $^{1} \cdot$ Angelo Franzini $^{1}$
}

Published online: 18 October 2017

(C) Springer-Verlag GmbH Austria 2017

Correction to: Acta Neurochir (2011) 153:207-208.

https://doi.org/10.1007/s00701-010-0795-2

The original version of this article unfortunately contained mistakes. The names of all authors are inadvertently inverted and are now corrected in the authorgroup of this article.

The online version of the original article can be found at https://doi.org/ 10.1007/s00701-010-0795-2.

$\triangle$ Giuseppe Messina giusmex@gmail.com

1 Department of Neurosurgery, Fondazione Istituto Nazionale Neurologico "C. Besta", Milan, Italy 